\title{
Research on the Theoretical Framework and Practical Form of Provincial Lifelong Education Community
}

\author{
Jixian Zhang \\ Department of Zhejiang Open University, Hangzhou, China \\ Email:2495000327@qq.com
}

How to cite this paper: Zhang, J.X. (2020) Research on the Theoretical Framework and Practical Form of Provincial Lifelong Education Community. Open Access Library Journal, 7: e6287.

https://doi.org/10.4236/oalib.1106287

Received: April 1, 2020

Accepted: April 19, 2020

Published: April 22, 2020

Copyright $\odot 2020$ by author(s) and Open Access Library Inc.

This work is licensed under the Creative

Commons Attribution International

License (CC BY 4.0).

http://creativecommons.org/licenses/by/4.0/

\section{(c) (i) Open Access}

\begin{abstract}
Based on the community theory, this paper puts forward the overall structure of provincial lifelong education community from four aspects: hierarchy structure, function structure, operation structure and content structure, and explains the overall structure of the three supporting systems of the lifelong education entity community, learning platform and resource community, and learning achievement certification and transformation community. Based on the exploration of China's "Yangtze River Delta" region, a "trinity" of open universities, shared platforms, and credit banks is proposed to build a lifelong education community from a practical level. Research suggests that to build an open, flexible, collaborative, and integrated provincial lifelong education community, it is also necessary to establish a policy guarantee mechanism, a collaborative linkage mechanism, a fusion and penetration mechanism, and a supervision and evaluation mechanism, etc.
\end{abstract}

\section{Subject Areas}

Adult Pedagogy

\section{Keywords}

Lifelong Education, Governance System, Community

\section{Introduction}

Over the past 40 years of reform and opening up, China's lifelong education has made significant progress in theory and practice, forming the development characteristics of Chinese characteristics [1]. In order to better serve the modernization of national governance system and governance capacity, and meet people's 
growing needs for a better life, in November 2019, it was clearly proposed to build an education system serving the lifelong learning of the whole people, take lifelong education as an important livelihood project to the national strategic level, and integrate the lifelong education governance system into the national basic public service system. This puts forward propositions such as lifelong education governance structure, core pillars and operation mechanism. Based on the community idea, this research project proposes to create the core pillar of lifelong education by creating an online and offline lifelong education community, and explores the theoretical structure, practice form and operating mechanism of the lifelong education community from a theoretical and practical perspective.

\section{Theoretical Basis of Lifelong Education Community}

Community exists in politics, economy, culture, education, law, science and other fields. There are national level community, regional level community, cultural community, development community, human destiny community, learning community and education community. The construction of lifelong education community is based on the "community" theory of Ferdinand Tonnies, the "development community" thought of Marx, as well as the theory of lifelong education and lifelong learning, to explore the structure, function, path and method of lifelong education governance system, and build the core pillar of lifelong education.

In community and society, Tonnies defined community as "a combination of groups formed through some positive relations, which play a role in internal and external uniformly, a combination of realistic and organic life combination" [2], emphasizing the "organic organization form" of community; Marx put forward the development community by using the principle of historical materialism thought, systematically elaborated the intermediary way of human and human, human and social common development, the reality of human social development and the coordinated development of human and society [3] [4]; With the development and application of community in the field of education, Sato, a Japanese scholar, points out that "high quality learning is more likely to be realized in community learning" and "learning community and deep learning are the ways to create future education reform" [5].

The connotation and extension of "educational community" are still in the process of generation, construction and constant change. Some researchers believe that "educational community" refers to the group of educators in the same educational paradigm, including the staff engaged in theoretical research, model construction, application promotion and educational teaching practice [6] [7]. Some community educators in China associate community with life-long education, and call the interaction and cooperation of some local community education functions as life-long education community from the concept and subjective level [8] [9]. However, they lack systematic research and practical explora- 
tion on the connotation, structure and mechanism of life-long education community.

The author thinks that the community in the lifelong education governance system should be an ecosystem with complete structure, perfect function and orderly operation. It has the characteristics of integrity, sharing, coordination and development. It emphasizes not only the needs of human lifelong development and social development, but also the top-level design of lifelong education community and the operation mechanism of collaborative sharing system, highlighting its core role in guiding the development of lifelong education and lifelong learning practice in the governance system.

\section{Theoretical Framework of Provincial Lifelong Education Community}

Dewey, an American educator, believes that "education is life" and "school is society" [10]. This means, complete education should be contained in family life, school life and social life. Therefore, the construction of provincial lifelong education community should take the provision of lifelong learning public services for all learners as the most value requirement, promote the transformation of lifelong learning achievement certification, build a lifelong education talent growth overpass, and finally realize the lifelong education vision of "no barriers to enrollment, everyone has books to read, where is the classroom, and can learn from time to time".

\subsection{Target Orientation}

The construction of lifelong education community should be based on the premise of obeying the modernization of national and regional governance system and governance ability, integrating local higher education, vocational education, community education and relevant social training institutions and other educational resources according to the development level of regional education and the lifelong development needs urban and rural residents, and using the latest development concept of lifelong education and the development achievements of modern information technology to open up. The core pillar of life-long education should be built with the concept of "free" and innovative thinking.

Specifically speaking, it is necessary to build a shared lifelong education intelligent learning platform for learners, explore the innovative mode of universal end-to-end learning, to improve the development level of provincial lifelong education, and to promote "young and old" in order to make up for the short board of provincial lifelong education, take the modern technology such as Internet, artificial intelligence and big data as the support, and take the opportunity of the construction of provincial open university balanced development and regional balanced development services.

Since the pre-school education and school education in the life-long education chain have established a relatively complete support system, while the post 
school continuing education and social education are relatively weak, the core task of the construction of the provincial life-long education community is to provide enterprises, villages and communities and other grassroots front-line personnel with learning to receive higher education and other kinds of education opportunity: to play a key role in the cultivation of new farmers, new industrial workers and new citizens, and promote community education and elderly education.

At the same time, we must make full use of modern information technology, optimize and improve the intelligent learning environment and learning support service ability, build a quick, convenient and resource rich one-stop cloud service platform and seamless learning environment for lifelong learning, [11] constantly optimize the lifelong learning environment, learning process and learning resource allocation through online and offline integration interaction and online teaching and learning behavior data analysis set, for each learner to provide high-quality, personalized, appropriate education, so that learners have a better learning experience and a better sense of learning.

\subsection{Basic Features}

Based on the goal orientation, the community of lifelong education should also embody the basic characteristics of openness, flexibility, coordination and integration. The openness is mainly reflected in the opening of education objects, learning platforms and resources. It is open to all members of the society and implements registered learning. Through learning and assessment, corresponding credits can be obtained. Corresponding credits can be exchanged for open university course certificates or academic certificates, etc. after certification. The flexibility is reflected in the way of learning and learning everywhere at all times. It is convenient and flexible to provide social members with convenient, flexible and humanized learning resources and learning environment by establishing the learning support service system based on the latest information technology such as Internet, big data and artificial intelligence; the synergy is reflected in the integrity and synergy of provincial lifelong education related institutions, including the accommodation between various types of education and provinces and cities collaboration of life-long education institution.

The integration is reflected in the deep integration of independent development and social development of lifelong education community, the deep integration of key development and all-round promotion, the deep integration of education service mode, localization and personalized needs, and the deep integration of modern information technology and learning support services.

\subsection{Basic Structure}

The basic idea of the structure design of the provincial lifelong education community should be guided by the community theory and Marx's development community thought, with the goal of serving the modernization of the lifelong education governance system and governance ability, to build an organic com- 
munity with the common value pursuit, common goal, common standard and common operation mechanism, and form the core pillar of the lifelong education governance system The architecture includes hierarchy, operation path, function structure and content structure (Figure 1). From the perspective of operation path, life-long education community can be divided into offline and online systems; from the perspective of support, it can also be summarized into three systems: life-long education entity community, learning platform and resource community, and learning achievement certification and transformation community.

\subsubsection{Entity Organization and Structure of Lifelong Education}

Based on China's administrative divisions, the provincial lifelong education entity community can build provincial, municipal, county, town, street and village (community) lifelong education entity institutions (temporarily referred to as "lifelong education complex"), which are endowed with different positioning and functions. According to the functional orientation, the entity community can be divided into provincial, municipal, county lifelong education subsystem and county, town (street), village (community) lifelong education subsystem (Figure 2). Among them, the county-level lifelong education complex is the key link between the two subsystems, and its overall governance capacity will directly affect the operation efficiency of the provincial lifelong education governance system. The reason why the entity community of lifelong education should be divided into two subsystems is mainly based on the consideration of function orientation and operation efficiency.

As far as the functional orientation is concerned, the provincial, municipal and county-level lifelong education complexes have the functions of guiding service, research and evaluation, organizing continuing education, community education and elderly education, and undertaking the transformation of learning achievement certification. Of course, when performing these functions, the three levels of province, city and county have their own emphasis. For example, the provincial life-long education complex focuses on the top-level design of life-long education monitoring, research, evaluation, etc., while the city and county complex is based on the overall planning of the provincial complex to carry out regional practical level monitoring and evaluation.

Under the guidance of county-level lifelong education institutions, town (street) and village (community) lifelong education institutions mainly undertake skills training, community education, elderly education tasks and rural cultural construction. Due to the lack of full-time personnel in charge of lifelong education in village level autonomous organizations, town (street) and village (community) lifelong education sub-systems end at town (street) level. The construction of physical education complex is the key. From the perspective of the whole provincial lifelong education governance system, the construction of the provincial, county (city, district) and town (street) lifelong education complex is the key. 


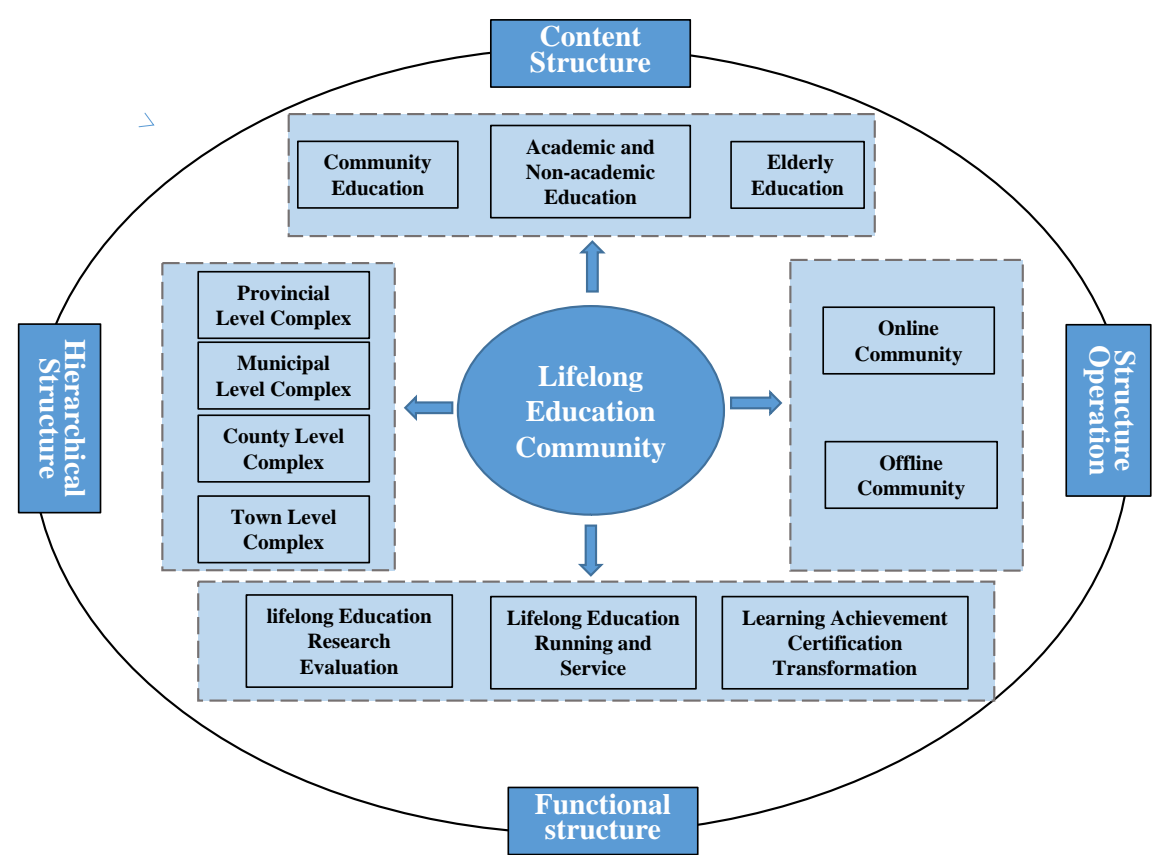

Figure 1. Theoretical framework of lifelong education community.

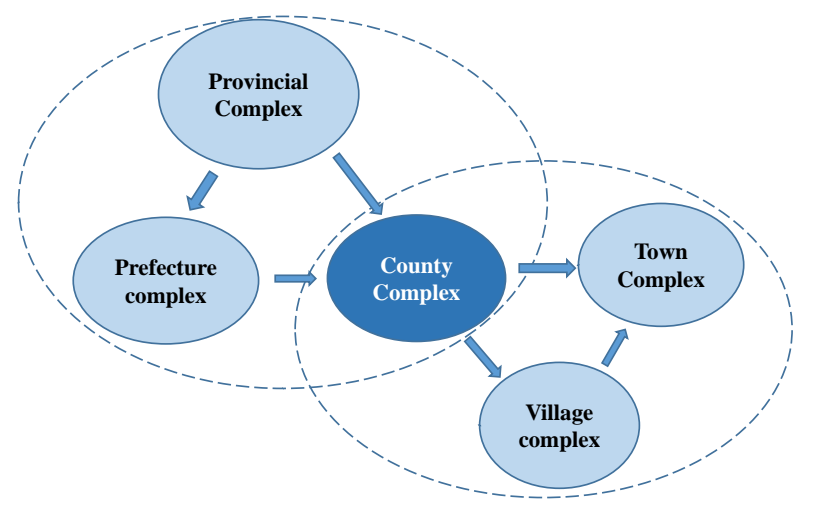

Figure 2. Two subsystems of provincial lifelong education entity community.

\subsubsection{Structure of Lifelong Learning Sharing Platform}

Under the background of information technology and global integration, building an online community of interconnection, collaboration and sharing is an inevitable requirement to meet the diversified and personalized needs of learners. The core of it is how to build a provincial, municipal and county integrated intelligent learning platform and a lifelong learning resource pool shared by the whole province. The construction of platform and resource community needs to make full use of the new generation of information technology, such as cloud computing, big data, mobile Internet, artificial intelligence and block chain to build an open intelligent learning platform and lifelong learning resource library for the society, promote the deep integration of lifelong education teaching, management and service and information technology, and promote the construction, sharing and sharing of lifelong education resources of the whole society. 
The platform function should realize six core functions: unified identity authentication, unified learning space, unified learning support, unified resource supply, unified standard system and unified data analysis (Figure 3). At the same time, it provides a unified standard interface for the functional docking of all kinds of learning platforms in the whole society, promotes information aggregation, service aggregation, resource aggregation and data aggregation, and realizes the co-construction and sharing of platforms, resources and data [12].

\subsubsection{Learning Achievement Certification Transformation System Architecture}

The certification, accumulation and transformation of lifelong learning achievements are the links of lifelong education community and the flyover of talent growth. Shanghai, Zhejiang, Guangdong and other provinces and national open universities have made a solid step in the construction of lifelong education credit bank [13]. However, due to the lagging influence of policy restrictions and the research on certification conversion standards, most of them are still in the stage of recording learning achievements and establishing learning archives at the application level, and the real credit conversion has not been pushed forward in a large range. In particular, how to identify the continuing education, social education and previous learning achievements, how to convert credits, how to convert achievements and other difficult problems have not yet been solved, and there is a lack of relatively perfect and referential policies, paths and methods.

Therefore, the construction and application of lifelong education credit bank should follow the principles of step-by-step, point by area, effective and practical. The principle of step-by-step is to gradually promote mutual recognition from single certification to two-way mutual recognition, from mutual recognition between adult education to mutual recognition between adult education and general education, and from mutual recognition between academic education to mutual recognition of all kinds of education at all levels; the principle of "point to area" is to implement in places with conditions, willingness and good policy basis, and gradually promote after accumulating experience; effective and practical. The principle is to provide effective and practical credit exchange according to the needs of learners, not only for academic education, but more to encourage lifelong learning.

From the perspective of theoretical research and practical results, the provincial lifelong education credit bank system architecture includes offline organizational structure and online credit bank management platform. Offline organization system should include provincial management center, prefecture level and county (city, district) credit bank sub center, and township (street) acceptance point. In some industries and large enterprises, it can also be considered to set up sub center or acceptance point; online platform background management of credit bank should include user management, learning file management, credit certification management, credit conversion management and certificate management, etc. Module (Figure 4). 


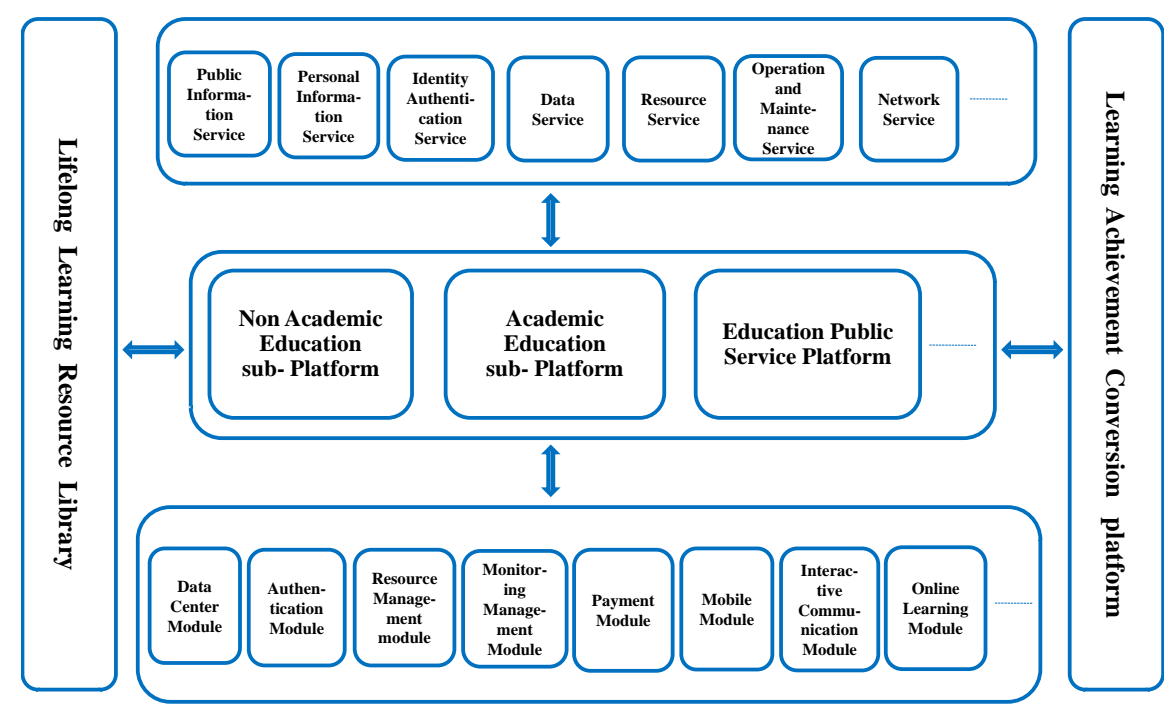

Figure 3. Basic structure of lifelong learning platform.

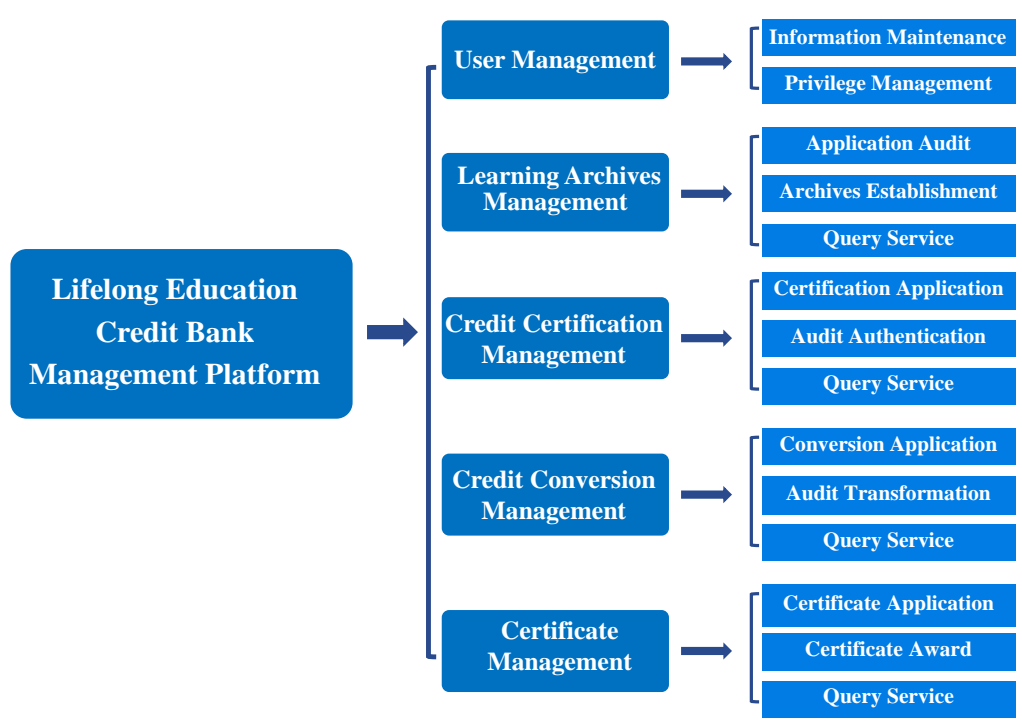

Figure 4. Provincial lifelong education credit bank background management module.

\section{Practice Form of Provincial Lifelong Education Community Construction}

Shanghai, Zhejiang and other Yangtze River Delta areas have preliminary exploration and accumulated some experience in the construction of lifelong education community. Shanghai has introduced, publicized and practiced the concept of lifelong education earlier [14]. It is relatively perfect in the construction of lifelong education governance system. It has established a learning society construction and lifelong education promotion committee, a lifelong education department in the municipal education commission, a Shanghai learning network, a Shanghai Open University, a lifelong education credit bank, and Shanghai Lifelong Education Promotion Ordinance. It can be said that all aspects of life-long education are basically reflected in Shanghai. According to the charac- 
teristics of the province, Zhejiang Province clearly proposes to build a learning society with lifelong learning and improve the level of lifelong education for all. According to the needs of the coordinated development of life-long education in urban and rural areas, the "last kilometer" problem of life-long education is solved by promoting the entity construction of life-long education in towns (streets) and vigorously promoting the construction of cultural auditoriums in villages (communities). At the same time, in the field of lifelong education and learning achievement certification transformation, the social training achievements of adult schools in the province have been put into the credit bank platform system, which lays the foundation for the certification of adult education and learning achievements [15]. Zhejiang Province also took the lead in setting up a Life-long Education Research and Evaluation Center at the provincial level in order to promote the high-quality development of life-long education.

With the purpose of serving the development of the times and the needs of regional development, the research and evaluation center has built an open, cross-border, collaborative and innovative research platform for lifelong education, devoted to scientific research, decision-making consultation, standard development, monitoring and evaluation of lifelong education, and provided theoretical basis for planning the development of lifelong education and strengthening quality monitoring. In view of Shanghai's special status and economic and social development level as an international metropolis, the development experience of lifelong education is often difficult to learn from in other provinces. However, Zhejiang Province, through the practice of "Open University, sharing platform and credit bank", "Trinity" to promote collaborative development of lifelong education, has a certain universal significance from the provincial level, so this paper takes Zhejiang Province as an example to analyze the construction of lifelong education community.

\subsection{Build the Entity Network of Lifelong Education with the Construction of Open University System as the Core}

The three-level open university system of province, city and county is not only the entity network of lifelong education, but also the centralized place where lifelong education credits can be used. With the Open University as the core, Zhejiang Province integrates all kinds of educational resources, such as higher education, community education, elderly education and farmer education, builds a school running and service system, a credit bank system for lifelong education, and a life-long education complex at the provincial, municipal and county levels, so as to realize the integration and connection of continuing education with academic qualifications and non academic education, and become the core pillar of regional lifelong education that promotes the growth of talents and the overall development of people.

The provincial, municipal and county open universities are the main body and school running body of the complex at all levels; The community and elderly 
education system includes the provincial, municipal, county and town (street) communities and elderly education institutions, as well as the village (community) cultural auditorium; The lifelong education credit banking system is composed of three levels of entity organizations, namely, the provincial management center, the municipal branch, and the county (city, district) sub center A unified provincial credit bank network platform for lifelong education has been established.

The provincial life-long education complex is composed of the provincial Open University (TVU), the provincial community education guidance center, the provincial Open University for the aged and the provincial research and evaluation center for life-long education, which performs the functions of running schools such as continuing education, community and education for the aged, as well as the functions of research consultation, monitoring and evaluation, guidance and service for life-long education. The establishment of provincial lifelong education research and evaluation center is an innovative measure to promote the high-quality development of lifelong education in Zhejiang province. The purpose is to promote the high-quality development of lifelong education through research, monitoring and evaluation, so that learners have a better sense of access.

The composition of life-long education complex at city level and county (city, district) level is similar, which is mainly composed of Local Open University (TV University), Community University, Open University for the elderly (College), farmers college, etc., and undertakes the functions of running schools such as holding continuing education, community and elderly education, farmers education and training, and life-long education guidance services. The life-long education complex below the county level consists of town (street) adult culture and technology school (community school, community education center) and village (community) culture auditorium.

In order to promote the construction of the village cultural auditorium in Zhejiang Province, the Provincial Department of Education, together with the Propaganda Department of the Provincial Party committee, issued the three-year action plan for promoting community education into the rural cultural auditorium (2019-2021), which proposed to build a rural cultural auditorium service system covering the whole province, with complete functions and continuously enhanced service capacity, to meet the lifelong learning and spiritual and cultural needs of the rural residents and promote the society. The district education and the rural cultural auditorium coordinate the construction and development, serve the rural revitalization and the beautiful rural construction [16].

\subsection{Build an Online University with the Construction of Zhejiang Learning Network as the Core}

Zhejiang Learning Network (Figure 5) is an integrated online learning platform 
for learners across the province. It integrates open university learning platform, lifelong learning platform, online open course sharing platform and lifelong learning resource library, and strives to build an online university with "enrollment, course (resource) learning, credit mutual recognition, classified guidance and precise service". Through online and offline integration interaction and online learning behavior data analysis, Zhejiang Learning Network provides accurate learning support services for all lifelong education learners, and builds a provincial integrated lifelong education intelligent learning environment and resource service platform.

Zhejiang learning network is a unified portal and learning platform for the online platform of Zhejiang lifelong education community (Figure 6), and it is interconnected with Zhejiang lifelong learning resource base and Zhejiang University online open curriculum sharing platform, providing lifelong learning resources and various quality academic education curriculum resources for all social learners, recording learning process and track.

Lifelong learning digital resource base is an open cloud service platform for resource management and application. Learning resources are classified, integrated and presented at different levels, and resources are accurately pushed based on user learning behavior analysis, covering cultural conservation, scientific literacy, health care, leisure skills, family education, career development, etc. At present, more than 30,000 learning resources have been gathered and constructed, which can provide resource support for continuing education, vocational training, community and elderly education [17]. The online open course sharing platform of colleges and universities is a high standard MOOCs platform in Zhejiang Province. It is not only a gathering place of high-quality educational resources such as colleges and universities, industrial enterprises and social institutions, but also an intelligent learning platform that provides high-quality academic education resources for the whole society. It has built a number of high-level general courses, characteristic courses of advantageous disciplines and emerging high-end courses, and gradually built a large scale Model open curriculum system. At present, 408 colleges and universities have settled in the platform, 775 MOOC courses and 94 SPOC courses have been opened, and more than 200,000 students have chosen courses.

Zhejiang lifelong learning digital learning resource base and online open course sharing platform of colleges and universities take into account the needs of non academic and academic education, and pay attention to the open sharing of courses and resources, which can effectively meet the needs of multi-level, diversified and personalized learning. At the same time, we should actively explore the operation methods of paid use of high-quality resources and compensation and incentive for resource providers, and attract colleges and universities, research and consulting institutions, industry enterprises, employers and social institutions to participate in the curriculum and resource construction, so as to achieve a sustainable market-oriented resource supply and demand mechanism. 


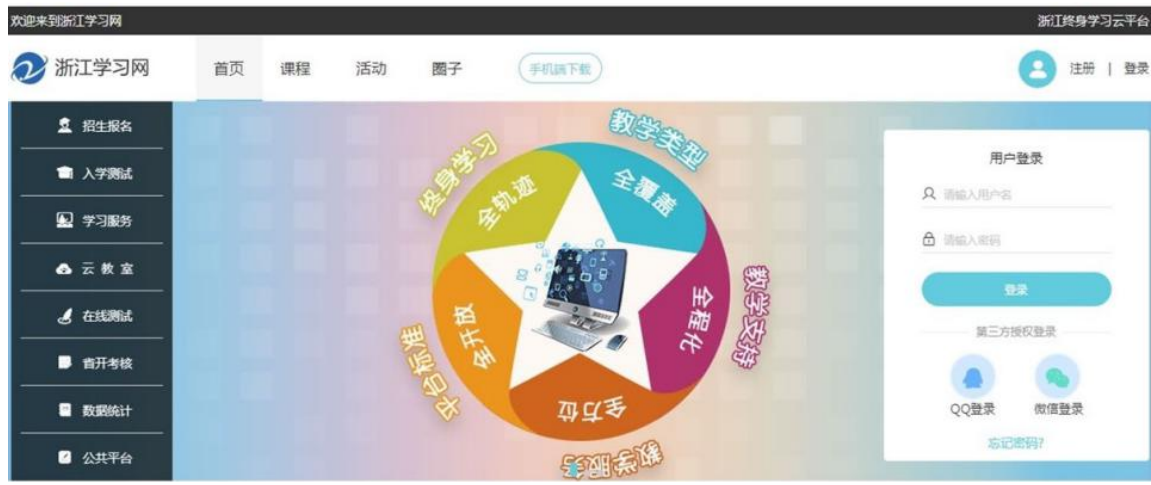

Figure 5. Homepage of Zhejiang learning network.

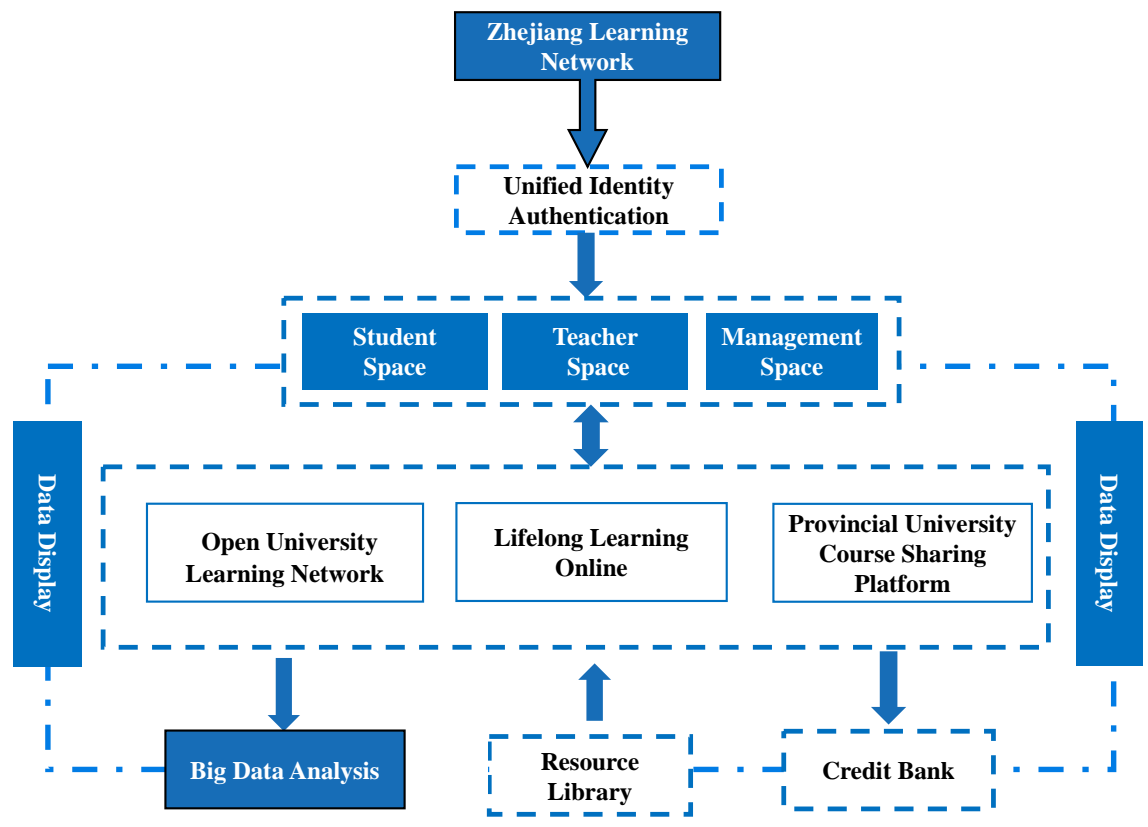

Figure 6. Logic structure of Zhejiang learning network.

\subsection{Build a Learning Achievement Certification Transformation Overpass with the Construction of Lifelong Education Credit Bank as the Core}

Zhejiang lifelong education credit bank is not only a management institution for certification, accumulation and transformation of lifelong learning achievements, but also an authoritative big data provider of lifelong education learning achievements in the province. Through the formulation and improvement of the standards and methods for credit recognition, accumulation and conversion, the pilot projects of credit mutual recognition and learning achievement conversion were carried out, and the projects such as the revitalization of rural talents, online open curriculum sharing in colleges and universities, and the promotion of academic qualifications of police auxiliary personnel were first promoted and applied. Zhejiang credit bank has established a provincial management center, 12 credit bank branches and 100 credit bank sub centers in the whole province. 
The service system covers the whole province. The number of credit bank accounts has exceeded 2 million. All the social training achievements of adult schools in the province have been deposited into the credit bank platform system [15].

\section{Operation Mechanism of Provincial Lifelong Education Community}

An effective community must have a good operation mechanism to guarantee. The author focuses on four aspects of operation policy and legal mechanism, coordination mechanism, integration mechanism and quality assurance mechanism.

\subsection{Policy Guarantee Mechanism}

For the efficient operation of the provincial lifelong education governance system, first of all, it is necessary to establish the provincial, municipal and county level lifelong education leadership institutions, to study and formulate the regional long-term development plan and relevant policies and systems, to study and solve the key and difficult problems and the problems that the learners pay close attention to, and to control and guarantee the healthy development of the provincial lifelong education. Secondly, we need to promote the legislation of lifelong education, raise the relevant lifelong education system to the legal level, solidify it in the form of law, and promote the provincial lifelong education governance to the track of legalization. In the aspect of lifelong education legislation, Fujian, Shanghai and other provinces and cities are at the forefront of the country, and have successively issued regulations on promoting lifelong education at the provincial and municipal levels, but practical innovation and improvement are still needed at the operational level of the regulations.

\subsection{Coordination and Linkage Mechanism}

In order to give full play to the core supporting role of lifelong education community and promote the modernization of provincial lifelong education governance ability, it is necessary to establish a collaborative mechanism of up-down linkage for the lifelong education complex at all levels established according to the administrative divisions. The establishment of collaborative linkage mechanism, first, needs to clarify the responsibilities and rights of multiple subjects within the lifelong education community; second, needs to design some projects and carriers as a link to drive the linkage of four levels of provinces, cities, counties and towns. Such as the construction of learning cities, lifelong education research and experimental projects; third, vigorously promote the publicity and education of lifelong education ideas and lifelong learning ideas, and constantly improve the awareness of cadres and masses on lifelong education, lifelong learning and its importance. Such as the national lifelong learning week at all levels held every year, organizing and carrying out relevant knowledge competitions, etc. 


\subsection{Integration Mechanism}

The integration mechanism is mainly the integration of lifelong learning platform, lifelong learning resource base and credit bank platform. It is necessary to solve the problems that platforms are not interconnected, learning resources are not shared, and learning achievements are not recorded uniformly in many places. It is necessary to establish an all-round online lifelong education integration mechanism with full open platform standards, full sharing of learning resources, full track of learning files and full range of learning services, so as to provide better learning experience for learners.

\subsection{Quality Monitoring Mechanism}

To promote the construction of provincial lifelong education governance system with high quality, we need to innovate and improve the construction of lifelong education research and evaluation team, regional lifelong education development quality and level monitoring, evaluation index design and result application, explore the establishment of a new era lifelong education supervision system and mechanism, and improve the authority and effectiveness of supervision and evaluation.

\section{Conclusion}

Community is a growing historical process, a process of continuous development and change from beginning to end [10]. The construction of a lifelong education community involves many issues such as the nature of lifelong education, the structure, level and shape of the main body of educational activities, and the reshaping and collaboration of internal relationships. It requires comprehensive and complex thinking. At present, the construction of the lifelong education community is still being explored and reformed. The organizational system, functional structure, operating mechanism and institutional culture need to be continuously improved. There are still many gaps from the true realization of the healthy and efficient operation of the lifelong education governance system. Departments, social institutions and learners should work together to create a good lifelong education environment, establish a benign interaction mechanism between lifelong education and environmental elements, and gradually form lifelong education and lifelong culture in order to achieve the coordinated development and high-quality development of regional lifelong education.

\section{Funding}

Zhejiang Natural Science Fund Project "Research on resource description system based on meta model under the background of big data" (Project No.: LY14F020039), Moderator: Zhang Jixian; National Education Science "13th Five Year Plan" 2019 key project of Ministry of Education "monitoring research on balanced development of urban and rural elderly education-Taking Yangtze 
River Delta as an example" (Project No.: DKA190449), moderator: Cheng Xianping.

\section{Conflicts of Interest}

The author declares no conflicts of interest regarding the publication of this paper.

\section{References}

[1] Wu, Z.M. (2018) Historical Review and Prospect of China's Lifelong Education in the 40 Years of Reform and Opening Up. Fudan University Education Forum, 6, 12-19.

[2] Tönnies, F. (1999) Community and Society. Trans. Lin, R.Y., Commercial Press, Beijing.

[3] Jiang, J.C. and Wang, P.X. (2012) Marx's Development Community Thought and Contemporary Enlightenment. Jiangsu Social Sciences, 6, 41-48.

[4] Yu, X.L. and Cai, X.L. (2012) The Possibility and Inevitability of Social Organization Construction in China-Based on the Perspective of Marxist Community Thought. Journal of Fujian Socialist University, 6, 94-96.

[5] Ruan, X.Z. (2017) On the Concept, Characteristics and Significance of Learning Community. Journal of Higher Education, 5, 193-194.

[6] Yan, Y.M. and Liang, B.G. (2002) Educational Paradigm and Educational Community. Journal of Uoyang Institute of Technology (Social Science Edition), 4, 82-87.

[7] Liu, Y. (2014) On the Connotation and Construction Principles of Educational Community. Contemporary Education Forum, 4, 35-42.

[8] Wang, Z. (2017) Model and Feature Analysis: Research on the Development of Lifelong Education Community in China. Vocational Education Forum, 27, 65-69.

[9] Chen, Y. (2015) Connotation, Characteristics and Construction Principles of Lifelong Education Community: From the Perspective of Quality of Community Education Resources. Vocational Education Communication, 34, 43-49.

[10] Dewey (1990) Democracy and Education. Trans. Wang, C.X., People's Education Press, Beijing.

[11] Lu, F., Yin, X.S. and Zhang, J.X. (2016) Seamless Learning Environment Design from the Perspective of Open University. Distance Education Journal, 2, 39-48.

[12] Lu, W.H. (2019) Connotation, Function and Implementation Path of Intelligent Adaptive Learning Platform from the Perspective of AI $+5 \mathrm{~g}-$ Based on the Concept of Intelligent Seamless Learning Environment. Distance Education Journal, 3, $38-46$.

[13] Qi, Y.L. (2019) The Current Situation, Difficulties and Countermeasures of Credit Bank Construction in China. Education and Occupation, 6, 78-83.

[14] Zhuang, J. (2012) Develop Lifelong Education and Promote the Construction of a Learning Society. Continuing Education, 11, 3-5.

[15] Li, Y. (2019) Applied Research of Credit Bank in the Perspective of Rural Revitalization. China Vocational and Technical Education, 36, 58-62.

[16] Department of Education of Zhejiang Province, Publicity Department of the CPC Zhejiang Provincial Committee (2019) Notice on Printing and Distributing the Three Year Action Plan for Promoting Community Education into Rural Cultural Auditorium (2019-2021). 
http://jyt.zj.gov.cn/art/2019/4/17/art_1532983_33374978.html

[17] Zhang, J.X., Yu, J.F., Shan, Y.G., et al. (2017) Research on the Construction of Cloud Service System of Lifelong Learning Resources and Its Collaborative Innovation Mechanism. Vocational Education Forum, 36, 53-59. 